\title{
The Role of Iron in the Pathogenesis of Atherosclerosis
}

\author{
P. KRAML ${ }^{1}$ \\ ${ }^{1}$ Second Department of Internal Medicine, Third Faculty of Medicine, Charles University and \\ University Hospital Královské Vinohrady, Prague, Czech Republic
}

Received November 1, 2016

Accepted December 27, 2016

\section{Summary}

Ferritin and increased iron stores first appeared on the list of cardiovascular risk factors more than 30 years ago and their causal role in the pathogenesis of atherosclerosis has been heavily discussed since the early 1990s. It seems that besides traditional factors such as hyperlipoproteinemia, hypertension, diabetes mellitus, obesity, physical inactivity, smoking and family history, high iron stores represent an additional parameter that could modify individual cardiovascular risk. The role of iron in the pathogenesis of atherosclerosis was originally primarily associated with its ability to catalyze the formation of highly reactive free oxygen radicals and the oxidation of atherogenic lipoproteins. Later, it became clear that the mechanism is more complex. Atherosclerosis is a chronic fibroproliferative inflammatory process and iron, through increased oxidation stress as well as directly, can control both native and adaptive immune responses. Within the arterial wall, iron affects all of the cell types that participate in the atherosclerotic process (monocytes/macrophages, endothelial cells, vascular smooth muscle cells and platelets). Most intracellular iron is bound in ferritin, whereas redox-active iron forms labile iron pool. Pro-inflammatory and anti-inflammatory macrophages within arterial plaque differ with regard to the amount of intracellular iron and most probably with regard to their labile iron pool. Yet, the relation between plasma ferritin and intracellular labile iron pool has not been fully clarified. Data from population studies document that the consumption of meat and lack of physical activity contribute to increased iron stores. Patients with hereditary hemochromatosis, despite extreme iron storage, do not show increased manifestation of atherosclerosis probably due to the low expression of hepcidin in macrophages.

\author{
Key words \\ Iron - Iron stores - Oxidative stress - Inflammation • \\ Macrophages • Atherosclerosis

\section{Corresponding author} \\ P. Kraml, Second Department of Internal Medicine, Third Faculty \\ of Medicine, Charles University and University Hospital Královské \\ Vinohrady, Šrobárova 50, 10034 Prague 10, Czech Republic. \\ E-mail: pavel.kraml@fnkv.cz
}

In 1981, Sullivan first proposed iron as a cardiovascular risk factor, suggesting that the lower incidence of cardiovascular disease (CVD) in premenopausal women compared to men and postmenopausal women could be explained by lower body iron stores. He hypothesized that iron depletion by regular phlebotomy may be protective (Sullivan 1981). Data from a prospective randomized study of 1,931 men from eastern Finland (Salonen et al. 1992) documented that in subjects with initial plasma ferritin concentration levels $>200 \mu \mathrm{g} / 1$ myocardial infarction occurred 2.2 times more often than in men with ferritin levels $<200 \mu \mathrm{g} / 1$ over a 5-year period. In a different study, Tuomainen et al. (1998) estimated body iron stores more precisely as the ratio of circulation transferrin receptor (TfR) to plasma ferritin concentrations, and showed that in men with higher stored iron (i.e. lower TfR/ferritin ratio) the risk of acute myocardial infarction was 2-3 times higher compared to a cohort with low iron stores over an average 6.4-year follow-up period. In the "Bruneck Study", Austrian authors observed a strong correlation between asymptomatic atherosclerosis in the carotid arteries and iron stores, both in men and women (Kiechl 
et al. 1994). The same authors showed in a prospective study that initial serum ferritin was one of the strongest predictors of overall progression of atherosclerosis (Kiechl et al. 1997). We also demonstrated in a cohort of healthy men that body iron stores positively correlated with asymptomatic carotid atherosclerosis (Syrovátka et al. 2011). To prove the causal association of iron with CVD risk, several prospective studies evaluating the impact of changes in iron status have been performed. Kiechl et al. (1997) further proved that over a five-year follow-up lowering stored iron had a protective effect on the development of cardiovascular disease. On the other hand, iron accumulation increased the risk of coronary heart disease. Drüeke et al. (2002) observed in patients with end-stage renal disease that individuals receiving i.v. iron supplementation had higher plasma ferritin, higher intima-media thickness in the common carotid artery and higher plasma concentrations of advanced oxidation protein products (AOPP) compared to control subjects with no iron supplementation. On the other hand, two studies independently proved that lowering iron stores by regular blood donation resulted in a significant decrease in CVD risk (Meyers et al. 2002, Salonen et al. 1998). However, it should be noted that blood donors may be healthier than the general population. In addition, iron chelation in patients with coronary vascular disease has been shown to be associated with improved endothelial function (Duffy et al. 2001). The role of iron in the pathogenesis of atherosclerosis has always been associated with enhanced oxidative stress. Iron participates in a redox reaction through the transfer of electrons between the ferrous $\left(\mathrm{Fe}^{2+}\right)$ and ferric $\left(\mathrm{Fe}^{3+}\right)$ states and catalyses the formation of highly reactive oxygen species, namely the hydroxyl radical $\left(\mathrm{OH}^{\cdot}\right)$ : $\mathrm{O}_{2}{ }^{--}+\mathrm{H}_{2} \mathrm{O}_{2} \rightarrow \mathrm{O}_{2}+\mathrm{OH}^{-}+\mathrm{OH}^{\cdot}$.

The catalytic effect of iron is described in the Fenton reaction (Table 1).

Table 1. The Fenton reaction.

$$
\begin{aligned}
& \mathrm{Fe}^{3+}+\mathrm{O}_{2}^{--} \rightarrow \mathrm{O}_{2}+\mathrm{Fe}^{2+} \\
& \mathrm{Fe}^{2+}+\mathrm{H}_{2} \mathrm{O}_{2} \rightarrow \mathrm{OH}^{-}+\mathrm{OH}^{-}+\mathrm{Fe}^{3+}
\end{aligned}
$$

$\mathrm{O}_{2}{ }^{--}$- superoxide, $\mathrm{O}_{2}-$ molecular oxygen, $\mathrm{OH}^{-}$- hydroxide anion, $\mathrm{OH}^{\cdot}$ - hydroxyl radical.

Highly reactive hydroxyl radicals cause the oxidative modification of lipids and proteins as well as DNA damage, and are also responsible for the impairment of cell proliferation, endothelial dysfunction and immune system alterations.

Oxidative modification of lipoproteins, namely low-density lipoproteins (LDL), remains one of the crucial events in atherogenesis. In this process, both lipid and protein moieties are altered. Reactive oxygen species (ROS) are prone to attack the chains of fatty acids (FA) (especially unsaturated FA) in triglycerides, cholesteryl esters and phospholipids, leading to the formation of free and esterified peroxides (conjugated dienes), hydroxides, malondialdehyde (MDA) and other aldehydes, pentane and other hydrocarbons. Cholesterol itself is mostly oxidized into 7-ketocholesterol, cholesterol- $\beta$-epoxide and 7- $\beta$-hydroxycholesterol. The oxidation products of phospholipids include lysophosphatidylcholine and other molecules. Apoproteins are transformed into carbonyls or proteolysed fragments with certain modified amino acids (cysteine, cystine, histidine, methionine, lysine, arginine, tryptophan, tyrosine) and lipid-protein adducts, such as lipofuscins (Parthasarathy et al. 2010). Oxidized LDL (oxLDL) is involved in atherosclerosis on several levels, especially: 1) endothelial activation and dysfunction, 2) activation of macrophages and their transformation into foam cells, 3) activation of innate and adaptive immune responses.

Most data concerning LDL oxidation come from in vitro studies that use different pro-oxidative agents, including iron (Steinberg et al. 1989, Chait and Heinecke 1994, Fuhrman et al. 1994). Both ferrous $\left(\mathrm{Fe}^{2+}\right)$ and ferric $\left(\mathrm{Fe}^{3+}\right)$ iron have been shown to be effective LDL oxidizers, and oxidative modification can occur even in lysosomes (Satchell and Leake 2012). There is evidence that LDL oxidation is mostly mediated by the cells of the arterial wall. However, increased concentration of oxLDL has been found in the plasma of patients with acute myocardial infarction, unstable and stable angina pectoris, as well as in subjects with type 2 diabetes mellitus (Ehara et al. 2001, Njajou et al. 2009).

On the other hand, some studies have repudiated the association between iron stores and atherosclerosis (Frey et al. 1994, Auer et al. 2002, Waalen et al. 2002). Opponents of the "iron hypothesis" mainly question the role of iron as an independent cardiovascular risk factor, since iron positively correlates with other risk parameters, namely LDL-cholesterol. In one prospective study, reduction of iron stores by regular phlebotomy at 6-month intervals over a 6-year period had no effect on all-cause mortality or death or on non-fatal myocardial infarction or stroke in patients with peripheral vascular 
disease. However, survival was significantly improved in subjects when iron reduction was initiated before the age of 60 (Zacharski et al. 2007). Since these results show a strong interaction with age, it may be speculated that lowering iron stores could be even more protective in the primary prevention of younger patients. The reason for the inconsistencies with data on iron is also connected to the differences and inaccuracies that arise when assessing stored iron (ferritin, transferrin, the $\mathrm{TfR} /$ ferritin ratio, etc.). Both ferritin and transferrin, which act as acute phase proteins, increase in patients with acute or chronic inflammation (Ahmed et al. 2012). Ferritin further increases in malignancies (both in solid tumors and leukemias) (Sackett et al. 2016).

Hereditary hemochromatosis (HFE) is a genetic disease characterized by iron overload due to increased iron resorption in the small intestine. Prevalence ranges from 1:200 to 1:400 in Caucasians of northern European ancestry. Over $90 \%$ of clinically manifest patients are homozygotes (Tyr/Tyr) for the HFE gene polymorphism, Cys282Tyr (rs1800562). The other most common genetic variant is His63Asp (rs1799945) but has much lower penetrance (Whittington 2002). Thus, it is likely that carriers of the mutation in the HFE gene are at higher cardiovascular risk. Indeed, several authors report an increase in cardiovascular events among Cys282Tyr (rs1800562) heterozygotes (Roest et al. 1999, Tuomainen et al. 1999, Rasmussen et al. 2001). However, further studies, including one meta-analysis of 53,880 subjects, found no support for these findings (Ellervik et al. 2005, van der A et al. 2008, Engberink et al. 2010). The Rotterdam Study, which analyzed the frequency of both the HFE Cys282Tyr (rs1800562) and His63Asp (rs1799945) gene polymorphisms, showed no significant relation to stroke or carotid artery atherosclerosis (Njajou et al. 2002). Thus, iron overload in HFE is not associated with increased cardiovascular risk, despite the reported increased oxidative stress in these individuals (Broedbaek et al. 2009). Some reports even speculate about the possible protective effect of HFE (especially in homozygous patients) against atherosclerosis (Miller et al. 1994). Iron metabolism in hereditary hemochromatosis is characterized by increased iron resorption and excessive deposition in tissues, namely the liver, pancreas, heart and pituitary gland. Iron resorption, plasma iron concentration and tissue distribution are regulated by hepcidin and ferroportin. In duodenal enterocytes, ferroportin located on the basolateral membrane enables the transport of dietary iron to the blood. The peptide hepcidin directly binds to ferroportin, thus inhibiting the efflux of intracellular iron. Since the homozygous form of HFE is associated with hepcidin deficiency (Lee and Beutler 2009), lack of hepcidin results in the overexpression of ferroportin in the duodenum and increased iron resorption, which is associated with systemic iron overload in tissues. In macrophages, however, lack of hepcidin and increased ferroportin-mediated iron efflux lead to a decrease in intracellular iron levels (Valenti et al. 2011). Monocytes/ macrophages play a key role in the pathogenesis of atherosclerosis and the amount of iron within these cells may be of crucial importance. Thus, the lower levels of intracellular iron in the macrophages of HFE patients, even of homozygous form, seem to protect against atherosclerosis.

In $\beta$-thalassemia and sickle cell anemia (hereditary disorders characterized by the synthesis of abnormal hemoglobin and increased plasma iron turnover), iron-dependent oxidative stress injury is associated with frequent hemolytic events. Heme, when released into circulation, increases the level of redoxactive iron. In addition, thalassemic patients suffer from iron overload due to increased iron absorption and regular erythrocyte transfusions. Cheung et al. (2002) demonstrated that patients with $\beta$-thalassemia had greater arterial stiffness and endothelial dysfunction than controls. In the ARIC Study, black patients with sickle cell trait had increased incidence of ischemic cerebrovascular stroke during a median follow-up of 22 years (Caughey et al. 2014).

\section{Iron and transformation of monocytes/ macrophages into foam cells}

Atherosclerosis is a chronic fibroproliferative inflammatory process characterized by thickening of the arterial intima and formation of atherosclerotic plaque. As described by Mallat et al. (2009), both innate and adaptive immunity are involved, resulting in atherosclerosis progression. Monocytes, the key cellular effectors of innate immunity, are attracted to activated endothelial cells by chemoattractants, e.g. macrophage chemoattractant protein-1 (MCP-1). Circulating monocytes adhere to the endothelial surface and become trapped by cytoadhesive molecules, e.g. vascular cytoadhesive molecule-1 (VCAM-1), intracellular adhesion molecule-1 (ICAM-1) or E-selectin. Subsequently, monocytes enter the subendothelial space 
of the arterial intima, become activated by macrophagecolony stimulating factor (M-CSF) (produced by T-lymphocytes, endothelial cells and macrophages themselves) and differentiate into macrophages. Both pro-inflammatory M1 macrophages and anti-inflammatory M2 macrophages have been detected in atherosclerotic plaque (Butcher and Galkina 2012). M1 macrophages, driven by interferon $\gamma$ (IFN- $\gamma$ ) and lipopolysaccharide (LPS), express on their surface scavenger receptors, through which oxidatively modified lipoproteins (oxLDL) are internalized. Macrophages then become overfilled with cholesteryl ester and transform into foam-cells. Moreover, experimental studies indicate that oxLDL in combination with $\beta 2$-glycoprotein I ( $\beta 2 \mathrm{GPI})$ triggers the formation of immune complexes with specific IgG antibodies, which are subsequently absorbed by macrophages via the $\mathrm{Fc} \gamma$ fragment (Kajiwara et al. 2007). Pro-inflammatory M1 macrophages also induce smooth muscle cell (SMC) proliferation and their migration from media into the arterial intima. Atherosclerotic advanced unstable lesions, which are characterized by a relatively large lipid-rich necrotic core, predominantly contain M1 macrophages. In addition, M1 macrophages may further destabilize atherosclerotic plaque by producing matrix metalloproteases (MMP-1, MMP-3, MMP-9) via the hydrolysis of collagen fibers within the fibrous cap (Ley et al. 2011).

On the other hand, the role of M2 macrophages in atherogenesis is more complicated. IL1- $\beta$, IL-4, IL-10 and IL-13 (produced by Th2 lymphocytes and mast cells) transform monocytes into M2 macrophages, which are known to promote the fibrotic process through the recruitment of fibroblasts and the production of connective fibers (Gordon and Martinez 2010). By producing anti-inflammatory cytokines (especially IL-4, IL-10, IL-13), M2 macrophages have a major impact on the deactivation of endothelial cells, Th1 lymphocytes and other macrophage populations. M2 cells promote plaque stability by inducing the proliferation of SMC and the production of collagen I (Medbury et al. 2013). Even though both M1 and M2 subtypes are found in the fibrous cap, M2 macrophages are associated with plaque stabilization. Unlike M1 cells, M2 macrophages lack scavenger receptors and are thus incapable of internalizing oxidized LDLs. However, M2 macrophages are also capable of producing various MMPs (MMP-9, MMP-12, MMP-13, MMP-14), which are used for clearing apoptotic cells and plaque remodeling. The roles of other macrophage subsets are still poorly understood from an atherosclerosis prospective. These phenotypes include Mhem (hemorrhage-associated macrophages), Mox (macrophages activated by oxidized phospholipids) and M4 (macrophages induced by hemoglobin, oxidized phospholipids or chemokine ligand 4).

M1 macrophages have low iron turnover, low expression of ferroportin, heme oxygenase-1 (HMOX1) and CD163 (a scavenger receptor responsible for internalizing the haptoglobin-hemoglobin complex) and are rich in ferritin and prone to iron accumulation. M2 macrophages have, in contrast to M1 cells, an iron-release phenotype through the higher expression of ferroportin, HMOX1 and scavenger receptor CD-163 and the lower expression of ferritin. M2 macrophages exhibit higher iron turnover (both uptake and efflux) but lower intracellular iron status (Recalcati et al. 2010). Since high body iron stores are associated with increased oxidation stress and inflammation, it seems plausible that pro-inflammatory stimuli lead to the polarization of monocytes into the M1 (iron-rich) phenotype (Fig. 1). In our study of cultivated THP-1 monocytes, we demonstrated that iron-loading with human transferrin was associated with native LDL oxidation, increased accumulation of oxLDL and scavenger receptor stimulation (Kraml et al. 2005). Oxidation stress and inflammation are closely related processes and one can be induced by the other. Although inflammatory cells produce reactive species, reactive oxygen and nitrogen species can serve as signaling molecules, which enhance pro-inflammatory gene expression in tissues (Anderson $e t$ al. 1994, Flohé et al. 1997). Intracellular iron is predominantly stored in ferritin $\left(\mathrm{Fe}^{3+}\right)$. However, a certain amount exists as a cytosolic labile iron pool (LIP), which indicates that redox-active iron catalyzes the formation of ROS from both endogenous and exogenous sources. LIP and ROS are strongly interrelated, as documented by iron import and iron chelation studies (Yuan et al. 2004). In one in vivo study, LIP catalyzed ROS-mediated oxidation/peroxidation of LDL in macrophages, endothelial cells and VSMCs, a process that can be prevented by using the iron chelator, deferiprone (Matthews et al. 1997). Lapenna et al. (2007) showed that LIP, such as low-molecular-weight iron from ex vivo carotid endarterectomy specimens, significantly correlates with plasma ferritin and markers of lipid peroxidation. However, the relation between LIP and intracellular ferritin as well as plasma ferritin has not been fully clarified. In a recent clinical study of ours, we measured LIP in circulating monocytes and demonstrated 
that patients with a history of cardiovascular events (CVE) had a significantly higher concentration of iron in their intracellular LIP than healthy controls and that LIP correlated with markers of atherosclerosis progression and arterial stiffness (Riško et al. 2017). Xiong et al. (2003) demonstrated in TNF- $\alpha$ and lipopolysaccharide (LPS) stimulated macrophages that intracellular label iron pool (iron not bound in ferritin) leads to IKK and NFkB activation through the toll-like receptor 4 (TLR4)-dependent signaling cascade (Xiong et al. 2003). The phagocytosis of erythrocytes in areas of intraplaque hemorrhage represents another mechanism of iron accumulation in macrophages (Yuan et al. 1996). However, more recent studies reveal that these macrophages represent a subtype distinct from M1 and M2 phenotypes (Boyle et al. 2011, Habib and Finn 2014). Macrophages in hemorrhage areas such as Mhem (hemorrhage-associated macrophages), which are similar to M2 macrophages, are characterized by high expression of CD163 (a receptor responsible for internalizing the haptoglobin-hemoglobin complex), ferroportin and HMOX1, making these cells prone to iron efflux. However, heme itself leads to the pro-inflammatory activation of M1 macrophages mediated by TLR-4 (Figueiredo et al. 2007). On the other hand, HMOX1 has significant atheroprotective effects due to its anti-inflammatory, anti-oxidant and anti-apoptotic properties.

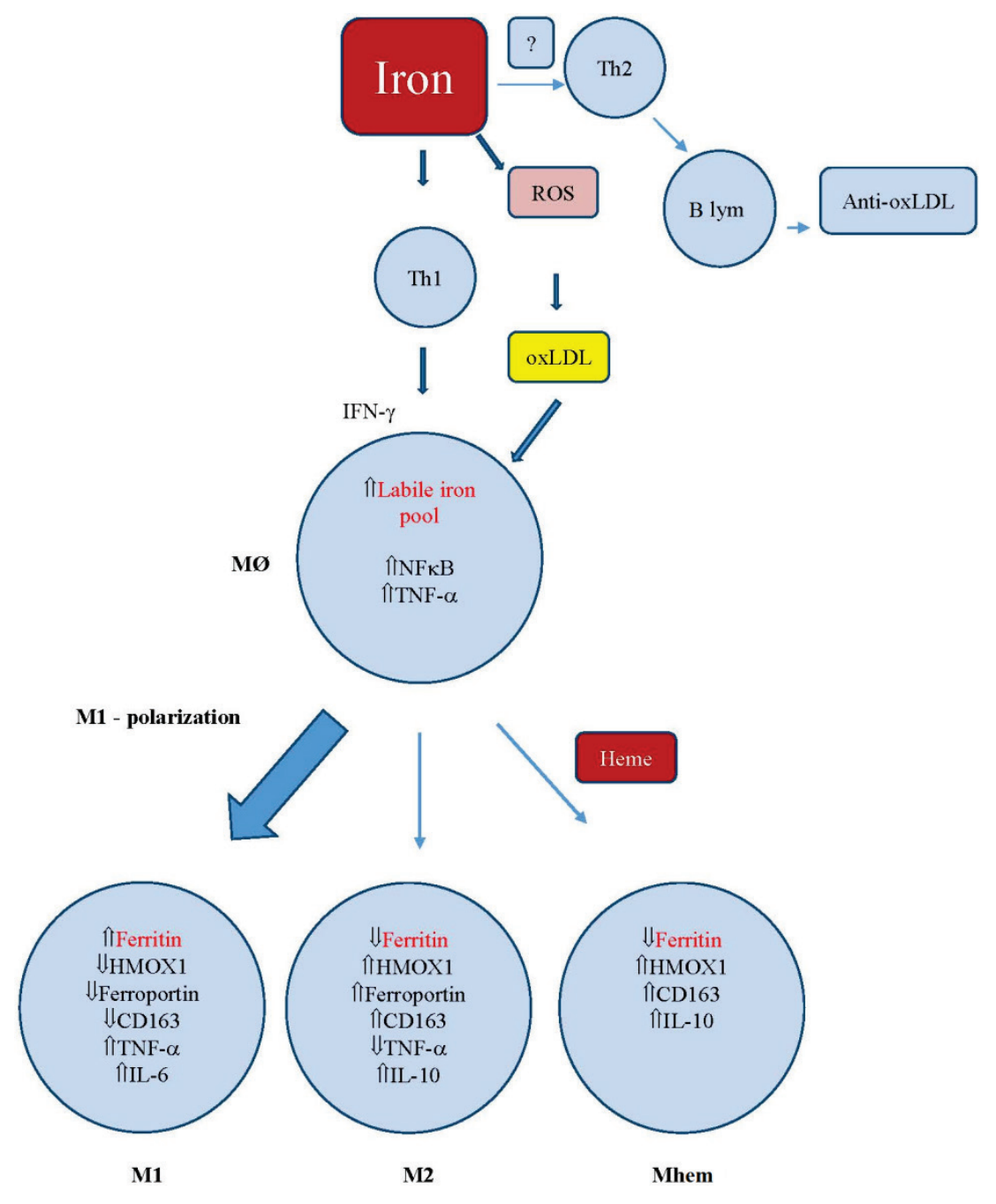

Fig. 1. Possible mechanism of iron influence on monocyte polarization.

Heme-oxygenase 1 plays one of the key roles in intracellular iron metabolism. This enzyme catalyses the degradation of heme into biliverdin, carbon monoxide and free iron, and subsequently converts biliverdin into bilirubin via bilirubin reductase. It has been shown that
HMOX1 is upregulated by oxidative stress and various inflammatory signals and that through its immunomodulatory and anti-inflammatory properties it drives macrophages into the M2 phenotype (Naito et al. 2014). Both biliverdin and bilirubin serve as antioxidants 
(Stocker et al. 1987) and carbon monoxide is a signal molecule with anti-inflammatory, anti-proliferative and vasodilatory properties. HMOX1 upregulates (directly or through carbon monoxide) the expression of anti-inflammatory interleukin 10 (IL-10) via the activation of phospho-p38 mitogen-activated protein kinase (p38MAPK). IL-10 itself also induces HMOX1 expression through the activation of signal transducer and activator of transcription 3 (STAT-3) and phosphatidylinositol 3-kinase (PI3K) (Naito et al. 2014). Of the two HMOX isoforms identified in humans - HMOX1 and HMOX2 - only HMOX1 is a stress-inducible enzyme. The gene expression of HMOX1 is regulated by various transcription factors, e.g. NFkB, hypoxia-inducible factor-1 and other signals such as mitogen-activated protein kinase (MAPK) and phosphatidylinositol 3-kinase (PI3K) cascades, depending on the character of the stressor and cell type (Paine et al. 2010). Iron released from heme by HMOX1 induces the expression of intracellular apoferritin, followed by the incorporation of iron into ferritin and the decrease of intracellular redox-active iron $\left(\mathrm{Fe}^{2+}\right)$ in the labile iron pool.

Ferritin is the main intracellular iron storage protein. Ferritin molecules are composed of heavy $(\mathrm{H})$ and light chains (L) and the ratios of $\mathrm{H}$ and $\mathrm{L}$ subunits vary among different tissues. It has been demonstrated that some ferritin (both $\mathrm{H}$ and $\mathrm{L}$ chains) is released into plasma and that $\mathrm{H}$-ferritin serves as a signal molecule and has an immunosuppressive function. The mechanism of ferritin secretion ( $\mathrm{H}$ and $\mathrm{L}$ chains) and its origin are not fully understood. However, Wesselius et al. (1994) documented ferritin secretion in hepatocytes and Kupffer cells. Ferritin binds to certain subsets of myeloid cells and $\mathrm{B}$ and $\mathrm{T}$ lymphocytes via the specific receptor TIM-2 (T-cell immunoglobulin and mucin domain 2) and has an inhibitory effect on cell proliferation (Recalcati et al. 2008). In mature myeloid cells as well as in myeloid precursors, ferritin inhibits cell migration and differentiation. Thus, the anti-inflammatory properties of plasma ferritin together with the incorporation of intracellular redox-active iron into apoferritin may protect against atherosclerosis. However, hyperferritinemia as a marker of elevated iron stores has been associated with increased cardiovascular risk. Higher oxidative stress and immune system activation associated with iron overload indicate the dysregulation of antioxidant and anti-inflammatory mechanisms in these individuals.

Oxysterols, products of the enzymatic and non-enzymatic oxidation of cholesterol, have also been shown to possess immunomodulatory properties. These bioactive molecules further regulate cholesterol and sphingolipid metabolism, platelet aggregation and apoptosis through interaction with specific sensors, e.g. liver $\mathrm{X}$ receptors (LXR) and oxysterol-binding protein (OSBP). Liu et al. (1997) documented that 25-OH-cholesterol, 7 $\beta-\mathrm{OH}$-cholesterol and other oxysterols stimulate the production of IL- 8 by human monocytes and macrophages isolated from atherosclerotic plaque. On the other hand, oxysterols in macrophages interfere with NFKB via LXRs, resulting in the inhibition of TLR-inducible inflammatory molecules, e.g. IL-1 $\beta$, MCP-1 (monocyte chemoattractant protein-1) and iNOS (inducible nitric oxide synthase) (Joseph et al. 2003).

\section{Iron, endothelial cells, vascular smooth muscle cells and thrombocytes in athero- genesis}

TLR-4-dependent signaling pathways seem to play a key role in atherosclerosis progression. Besides macrophages, TLR-4 is expressed in other cell types involved in atherosclerosis (endothelial cells, thrombocytes).

In endothelial cells TLR-4 activation upregulates the expression of chemoattractant and cytoadhesive molecules. Upon the administration of iron in healthy individuals, which induces the generation of superoxide anions in whole blood and endothelial dysfunction, a direct association has been reported between iron excess and endothelial dysfunction. Balla et al. (1990) demonstrated in an in vitro study that iron-loaded cultured endothelial cells that use iron-chelating fungistat 8-hydroxyquinoline are associated with cytotoxicity accompanied by membrane lipid peroxidation. In another study, cultivated human umbilical vein endothelial cells (HUVEV) loaded with non-transferrin-bound iron led to an increase in the intracellular labile iron pool and subsequent endothelial dysfunction associated with the induction of the adhesion molecules, VCAM-1, ICAM-1 and selectin (Kartikasari et al. 2004). This team further documented that iron-loaded endothelial cells exhibit enhanced activation and production of adhesion molecules in response to Cytomegalovirus (CMV) or Chlamydia pneumoniae (CHP) infection (Kartikasari et al. 2006). It has been suggested that increased intracellular iron may facilitate an endothelial response to various stimuli associated with the initiation and progression of atherosclerosis (namely, oxidized LDL), even though the causal roles of specific infectious agents, 
such as CMV and CHP, are no longer considered plausible. As demonstrated by experimental studies, oxLDL leads to the dysfunction of endothelial cells through the activation of PKC, MAPK and other signaling pathways (Ren et al. 2000, Li et al. 2003). Cominacini et al. (2000) proved in bovine endothelial cells that oxLDL activates transcription factor $\mathrm{NF \kappa B}$ via the enhanced intracellular production of free radicals.

Vascular smooth muscle cells (VSMC) in arterial media are also largely regulated by TLR-4. Under TLR-4-dependent activation, these cells proliferate and migrate into the intima (Pasterkamp et al. 2004). This process is accompanied by a phenotype change from the contractile to the synthetic, which produces an extracellular matrix rich in collagen leading to the formation of a fibrous cap. As documented by several in vitro studies, there is close cooperation between macrophages and VSMCs. Macrophages control VSMC activation via the production of IL-6 and platelet-derived growth factor (PDGF) (Zhu et al. 2000, Morisaki et al. 1992). It is reasonable to assume that intracellular iron in M1 macrophages indirectly promotes the activation of VSMCs in atherosclerosis. Moreover, iron chelation with desferrioxamine (DFO) significantly inhibited VSMC proliferation in one in vitro study (Wong et al. 2012).

Increased activation of thrombocytes via TLR-4 can lead to the formation of thrombi on the surface of unstable plaque (Jayachandran et al. 2010). In addition, changes in redox status substantially alter platelet activity. It has been documented that thrombocytes are capable of ROS production and that superoxide anions derived from platelets and other vascular sources promote platelet aggregation (Handin et al. 1977). As demonstrated by Praticò et al. (1999) in isolated human platelets, iron $\left(\mathrm{Fe}^{2+}\right)$ can directly stimulate aggregation through hydroxyl radical $\left(\mathrm{OH}^{\circ}\right)$ formation and protein kinase C (PKC) activation. DFO may inhibit collageninduced aggregation in this model.

\section{Iron stores, dietary iron and physical activity}

The recommended dietary iron intake in men and postmenopausal women is $8 \mathrm{mg} /$ day, and in premenopausal women $18 \mathrm{mg} /$ day (in pregnancy $27 \mathrm{mg} /$ day and during lactation $9 \mathrm{mg}$ /day (Institute of Medicine, Food and Nutrition Board 2001). In population studies, concentrations of plasma ferritin are used for assessing iron stores in the body. The reference interval in adults is $30-400 \mu \mathrm{g} / 1$ (men, aged 20-60 years),
15-150 $\mu \mathrm{g} / \mathrm{l}$ (women, aged 17-60 years). In general, serum ferritin in adults between 20-50 years of age ranges from 15-300 $\mu \mathrm{g} / \mathrm{l}$ (Association for Clinical Biochemistry 2012). In a cohort of Finnish men, the risk of coronary heart disease was significantly associated with iron intake. For each milligram of consumed iron, there was a $5 \%$ increase in CHD risk (Salonen et al. 1992). Other studies that evaluate dietary iron intake with respect to CHD show rather conflicting data, but most of these reports do not analyze the iron source. It later became obvious that the problem is associated with heme iron intake and the consumption of meat and meat products. Heme iron from hemoglobin and myoglobin represents $10-15 \%$ of the total iron intake in meat-eating populations, but over $40 \%$ of absorbed iron is heme iron due to its higher bioavailability (Carpenter et al. 1992). As shown by Snowdon et al. (1984), there was a $60 \%$ increase in the risk of fatal coronary events among men who consumed meat 6 times a week compared with men who consumed meat less than once a week. Increased risk of non-fatal myocardial infarction or fatal ischemic cardiac events with elevated heme iron intake are further supported by other studies (Ascherio et al. 1994, Klipstein-Grobusch et al. 1999). Risk estimates from pooled analyses and meta-analyses based on at least six cohorts document a significant $24 \%$ increase in cardiovascular mortality when $50 \mathrm{~g}$ of processed meat is consumed daily (Wolk 2017). In a study by Micha et al. (2012) a daily intake of $50 \mathrm{~g}$ of processed meat was associated with a $30 \%$ higher rate of CVD $(\mathrm{RR}=1.30$; $95 \% \mathrm{CI}=1.17-1.45)$. Bioavailability of dietary iron, which comes from hemoglobin and myoglobin in meat, is much higher than from other sources since the absorption of heme iron is not inhibited by negative feedback in response to plasma ferritin, as distinct from the absorption of non-heme iron (Hunt et al. 2000). Iron from animal sources contributes to only $10-15 \%$ of total dietary iron. However, over $40 \%$ of absorbed iron is represented by heme iron (Hurrell and Egli 2010) and its absorption is further facilitated by animal proteins. Iron absorption inhibitors, namely phytates, polyphenols, soy proteins, casein, whey and egg white, only decrease non-heme iron absorption. Calcium was believed to have an inhibitory effect on both non-heme and heme iron absorption (Cook et al. 1991, Hallberg et al. 1991). However, in one study, the addition of $200 \mathrm{mg}$ of calcium to a maize-based diet had no such effect (Troesch et al. 2009) (Table 2 and Table 3 ). 
Table 2. Iron absorption inhibitors.

\begin{tabular}{|c|c|}
\hline Name & Dietary source \\
\hline Phytate & Cereals, grains \\
\hline Polyphenols & $\begin{array}{l}\text { Fruit, vegetables, cereals, legumes, } \\
\text { tea, coffee, wine }\end{array}$ \\
\hline Soy proteins & Soybean \\
\hline Calcium & Milk products \\
\hline Casein, whey & Milk \\
\hline Egg white & Eggs \\
\hline
\end{tabular}

Table 3. Iron absorption enhancers.

\begin{tabular}{ll}
\hline Name & Dietary source \\
\hline $\begin{array}{ll}\text { Ascorbic acid } \\
\text { Muscle proteins }\end{array}$ & $\begin{array}{l}\text { Fruit, vegetables, supplements } \\
\text { Pork, beef, chicken, fish }\end{array}$ \\
\hline
\end{tabular}

Another discussed mechanism that contributes to iron overload seems to be low physical activity. Lauffer et al. (1981) outlines the possible mechanisms by which physical training promotes iron excretion. These include a) iron losses by sweating, b) gastrointestinal tract losses due to relative intestinal ischemia or stress gastritis, c) intravascular hemolysis with hemoglobinuria due to mechanic or osmotic destruction of erythrocytes, d) early release of iron from transferrin due to intermittent relative acidosis and e) increase of muscle mass associated with the enhanced incorporation of iron into myoglobin (Lauffer et al. 1991).

Thirty-five years ago in his iron hypothesis, Sullivan (1981) proposed that lower ferritin in premenopausal women due to monthly iron loss has a protective effect against atherosclerosis. The incidence of coronary heart disease and stroke in premenopausal women is indeed lower than in men of the same age and the risk increases after the menopause. Moreover, the Framingham Heart Study and the Multi-Ethnic Study of Atherosclerosis (MESA) showed that early menopause increases cardiovascular events (Lisabeth et al. 2009, Wellons et al. 2012). The lower CVD risk in premenopausal women has been sometimes attributed to the direct effect of estrogens. However, the results of MESA found no association between plasma estradiol and markers of subclinical atherosclerosis - intima-media thickness (IMT) or the coronary calcium score (Ouyang et al. 2009).

\section{Lower iron, lower hemoglobin and CVD risk}

Not only iron overload but also iron deficiency and chronic anemia are associated with increased cardiovascular risk, which suggests that the relationship between iron and CVD is not linear but rather U-shaped (Shoji et al. 2016). In one prospective cohort of the ARIC Study, the presence of anemia (defined as a hemoglobin concentration $<130 \mathrm{~g} / 1$ in men and $<120 \mathrm{~g} / 1$ in women) was independently associated with increased risk of CVD (HR 1.41 [95 \% CI: 1.01, 1.95]) (Sarnak et al. 2002). Results from the "Ludwigshafen Risk and Cardiovascular Health Study" showed that OR for CAD in the lowest quartiles of hemoglobin was 1.40 (95\% CI: 1.04, 1.90) compared to the highest gender-specific quartiles when adjusting for iron and ferritin. The authors suggested that both hemoglobin levels and iron status have an independent impact on CVD risk (Grammer et al. 2014). The association between anemia and CVD risk has traditionally been seen in terms of the worsening of myocardial ischemia. In addition, chronic anemia may lead to ventricular remodeling and heart failure. Increased cardiac output and high sympathoadrenal activity caused by anemia may result in left ventricular hypertrophy. Anemia further accompanies other CVD risk factors such as chronic kidney disease (CKD), chronic inflammatory processes and low nutritional status. Apart from oxygen transport, iron is involved in mitochondrial function, the metabolism of lipids and proteins and DNA synthesis. Iron depletion may thus lead to the impaired function of different tissues, namely the central nervous system, muscle tissue, the myocardium, the immune system and the thyroid gland. However, most patients with depleted iron stores develop anemia and, therefore, the question whether iron deficiency might contribute to atherosclerosis irrespective of hemoglobin concentrations remains unclear.

\section{Conclusion}

In addition to traditional risk factors, such as hypertension, hyperlipoproteinemia, diabetes, obesity, lack of physical activity and smoking, iron seems to play an important role in the pathogenesis of atherosclerosis, as documented by both observational and experimental studies. Iron mediates the oxidative modification of lipoproteins and through its pro-inflammatory properties impacts the initiation, progression and destabilization of atherosclerotic plaque. In patients where high body iron 
stores represent an additional cardiovascular risk factor, limiting meat consumption and increasing physical activity seem plausible countermeasures and should be added to the list of traditional "healthy life-style" recommendations. However, further research is required in order to formulate guidelines for an exact "iron diet", sufficient physical activity and, potentially, iron chelation, especially in patients at high cardiovascular risk and with elevated body iron stores.

\section{Conflict of Interest}

There is no conflict of interest.

\section{Acknowledgements}

Supported by the program PRVOUK P31.

\section{References}

AHMED MS, JADHAV AB, HASSAN A, MENG QH: Acute phase reactants as novel predictors of cardiovascular disease. ISRN Inflammation 2012: 953461, 2012.

ANDERSON MT, STAAL FJT, GITLER C, HERZENBERG LA: Separation of oxidant-initiated and redox-regulated steps in the NF-kB signal transduction pathway. Proc Natl Acad Sci U S A 91: 11527-11531, 1994.

ASCHERIO A, WILLETT WC, RIMM EB, GIOVANNUCCI EL, STAMPFER MJ: Dietary iron intake and risk of coronary disease among men. Circulation 89: 969-974, 1994.

ASSOCIATION FOR CLINICAL BIOCHEMISTRY 2012: http://www.acb.org.uk/Nat\%20Lab\%20Med\%20Hbk/ Ferritin.pdf

AUER J, RAMER M, BERENT R, WEBER T, LASSNIG E, EBER B: Body iron stores and coronary atherosclerosis assessed by coronary angiography. Nutr Metab Cardiovasc Dis 12: 282-290, 2002.

BALLA G, VERCELLOTTI GM, EATON W, JACOB HS: Iron loading of endothelial cell augments oxidant damage. J Lab Clin Med 116: 546-554, 1990.

BOYLE JJ, JOHNS M, LO J, CHIODINI A, AMBROSE N, EVANS PC: Heme induces heme oxygenase 1 via Nrf2: role in the homeostatic macrophage response to intraplaque hemorrhage. Arterioscler Thromb Vasc Biol 31: 2685-2691, 2011.

BROEDBAEK K, POULSEN HE, WEIMANN A, KOM GD, SCHWEDHELM E, NIELSEN P, BÖGER RH: Urinary excretion of biomarkers of oxidatively damaged DNA and RNA in hereditary hemochromatosis. Free Radic Biol Med 47: 1230-1233, 2009.

BUTCHER MJ, GALKINA EV: Phenotypic and functional heterogeneity of macrophages and dendritic cell subsets in the healthy and atherosclerosis-prone aorta. Front Physiol 3: 44, 2012.

CARPENTER CE, MAHONEY AW: Contributions of heme and nonheme iron to human nutrition. Crit Rev Food Sci Nutr 31: 333-367, 1992.

CAUGHEY MC, LOEHR LR, KEY NS, DEREBAIL VK, GOTTESMAN RF, KSHIRSAGAR AV, GROVE ML, HEISS G: Sickle cell trait and incident ischemic stroke in the atherosclerosis risk on communities study. Stroke 45: 2863-2867, 2014.

CHAIT A, HEINECKE JW: Lipoprotein modification: cellular mechanisms. Curr Opin Lipidol 5: 365-370, 1994.

CHEUNG YF, CHAN GC, HA SY: Arterial stiffness and endothelial function in patients with beta-thalassemia major. Circulation 106: 2561-2566, 2002.

COMINACINI L, PASSINI AF, GARBIN U, DAVOLI A, TOSETTI ML, CAMPAGNOLA M: Oxidized low density lipoprotein (ox-LDL) binding to ox-LDL receptor-1 in endothelial cells induces the activation of NF-kappaB through an increased production of intracellular reactive oxygen species. J Biol Chem 28: 12633-12638, 2000.

COOK JD, DASSENKO SA, WHITTAKER P: Calcium supplementation-effect on iron-absorption. Am J Clin Nutr 53: 106-111, 1991.

DRÜEKE T, WITKO-SARSAT V, MASSY Z, DESCAMPS-LATSCHA B, GUERIN AP, MARCHAIS SJ, GAUSSON V, LONDON GM: Iron therapy, advanced oxidation protein products, and carotid intima-media thickness in end-stage renal disease. Circulation 106: 2212-2217, 2002.

DUFFY SJ, BIEGELSEN ES, HOLBROOK M, RUSSEL JD, GOKCE N, KEANEY JF JR, VITA JA: Iron chelation improves endothelial function in patients with coronary artery disease. Circulation 103: 2799-2784, 2001. 
EHARA S, UEDA M, NARUKO T, HAZE K, ITOH A, OTSUKA M: Elevated levels of oxidized low density lipoprotein show a positive relationship with the severity of acute coronary syndromes. Circulation 103: 1930-1932, 2001.

ELLERVIK C, TYBJAERG-HANSEN A, GRANDE P, APPLEYARD M, NORDESTGAARD BG: Hereditary hemochromatosis and risk of ischemic heart disease: a prospective study and a case-control study. Circulation 112: 185-193, 2005.

ENGBERINK MF, POVEL CM, DURGA J, SWINKELS DW, DE KORT WL, SHOUTEN EG, VERHOEF P, GELEIJNSE JM: Hemochromatosis (HFE) genotype and atherosclerosis: increased susceptibility to iron-induced vascular damage in C282Y carriers? Atherosclerosis 211: 520-525, 2010.

FIGUEIREDO RT, FERNANDEZ PL, MOURAO-SA DS, PORTO BN, DUTRA FF, ALVES LS: Characterization of heme as activator of Toll-like receptor 4. J Biol Chem 282: 20221-20229, 2007.

FLOHÉ L, BRIGELIUS-FLOHÉ R, SALIOU C, TRABER MG, PACKER L: Redox regulation of NF- $\kappa B$ activation. Free Radic Biol Med 22: 1115-1126, 1997.

FREY GH, KRIDER DW: Serum ferritin and myocardial infarction. $W$ V Med J 90: 13-15, 1994.

FUHRMAN B, OIKNINE J, AVIRAM M: Iron induces lipid peroxidation in cultured macrophages, increases their ability to oxidatively modify LDL, and affects their secretory properties. Atherosclerosis 111: 65-78, 1994.

GORDON S, MARTINEZ FO: Alternative activation of macrophages: mechanism and functions. Immunity 32: 593-604, 2010.

GRAMMER TB, KLEBER M, SILBERNAGEL G, PILZ S, SCHARNAGL H, TOMASCHITZ A, KÖNIG W, MÄRZ W: Hemoglobin, iron metabolism and angiographic coronary artery disease (The Ludwigshafen Risk Cardiovascular Health Study). Atherosclerosis 236: 292-300, 2014.

HABIB A, FINN V: The role of iron metabolism as a mediator of macrophage inflammation and lipid handling in atherosclerosis. Front Pharmacol 5: 195, 2014.

HALLBERG L, BRUNE M, ERLANDSSON M, SANDBERG AS, ROSSANDERHULTEN L: Calcium-effect of different amounts on nonheme-iron and heme-iron absorption in humans. Am J Clin Nutr 53: 112-119, 1991.

HANDIN RI, KARABIN R, BOXER GJ: Enhancement of platelet function by superoxide anion. $J$ Clin Invest 59: 959-965, 1977.

HUNT JR, ROUGHEAD ZK: Adaptation of iron absorption in men consuming diets with high or low iron bioavailability. Am J Clin Nutr 71: 94-102, 2000.

HURRELL R, EGLI I: Iron bioavailability and dietary references values. Am J Clin Nutr 91 (Suppl): 1461S-1467S, 2010.

INSTITUTE OF MEDICINE, FOOD AND NUTRITION BOARD: Dietary reference intakes for vitamin A, vitamin K, arsenic, boron, chromium, copper, iodine, iron, manganese, molybdenum, nickel, silicon, vanadium and zinc: A report of the Panel of Micronutrients. Washington DC: National Academy Press, 2001.

JAYACHANDRAN M, MILLER VM, BRUNN GJ, OWEN WG: Platelet response as a sentinel marker of toll-like receptor 4 activation in mice. Thromb Res 126: 414-417, 2010.

JOSEPH SB, CASTRILLO A, LAFITTE BA, MANGELSDORF DF, TONTONOZ P: Reciprocal regulation of inflammation and lipid metabolism by liver X receptors. Nat Med 9: 213-219, 2003.

KAJIWARA T, YASUDA T, MATSUURA E: Intracellular trafficking of $\beta 2$-glycoprotein I complexes with lipid vesicles in macrophages: implication on the development of antiphospholipid syndrome. $J$ Autoimmun 29: 164-173, 2007.

KARTIKASARI AER, GEORGIOU NA, VISSEREN FLJ, VAN KATS-RANAUD H, VAN ASBECK BS, MARX JJM: Intracellular labile iron modulates adhesion of human monocytes to human endothelial cells. Arterioscler Thromb Vasc Biol 24: 2257-2262, 2004.

KARTIKASARI AER, GEORGIOU NA, DE GEEST M, VAN KATS-RENAUD JH, BOUWMAN JJM, VAN ASBECK BS, MARX JJM, VISSEREN FLJ: Iron enhances endothelial cell activation in response to Cytomegalovirus or Chlamydia pneumoniae infection. Eur J Clin Invest 36: 743-752, 2006.

KIECHL S, AICHNER F, GERSTENBRAND F, EGGER G, MAIR A, RUNGGER G, SPÖGLER F, JAROSCH E, OBERHOLLENZER F, WILLEIT J: Body iron stores and presence of carotid atherosclerosis. Results from the Bruneck Study. Arterioscler Thromb 14: 1625-1630, 1994. 
KIECHL S, WILLEIT J, EGGER G, POEWE W, OBERHOLLENZER F: Body iron stores and risk of carotid atherosclerosis. Circulation 96: 3300-3307, 1997.

KLIPSTEIN-GROBUSCH K, KOSTER JF, GROBBEE DE, LINDEMANS J, BOEING H, HOFMAN A, WITTEMAN JCM: Serum ferritin and risk of myocardial infarction in elderly: the Rotterdam study. Am J Clin Nutr 69: 1231-1236, 1999.

KRAML PJ, KLEIN RL, HUANG Y, NAREIKA Y, LOPES-VIRELLA MF: Iron loading increases cholesterol accumulation and macrophage scavenger receptor I expression in THP-1 mononuclear phagocytes. Metabolism 54: 453-459, 2005.

LAPENNA D, PIERDOMENICO SD, CIOFANI G, UCCHINO S, NERI M, GIAMBERARDINO MA, CUCCURULLO F: Association of body iron stores with low molecular weight iron and oxidant damage of human atherosclerotic plaques. Free Radic Biol Med 42: 492-498, 2007.

LAUFFER RB: Exercise and prevention: do the health benefits derive in part from lower iron levels? Med Hypotheses 35: 103-107, 1991.

LEE PL, BEUTLER E: Regulation of hepcidin and iron-overload disease. Annu Rev Pathol 4: 489-515, 2009.

LEY K, MILLER YI, HEDRICK CC: Monocyte and macrophage dynamics during atherogenesis. Arterioscler Thromb Vasc Biol 31: 1506-1516, 2011.

LI D, LIU L, CHEN H, SAWAMURA T, MEHTA JL: LOX-1 mediates oxidized LDL-induced the expression and activation of matrix metalloproteinases (MMPs) in human coronary artery endothelial cells. Circulation 107: 612-617, 2003.

LISABETH LD, BEISER AS, BROWN DL, MURABITO JM, KELLY-HAYES ML, WOLF PA: Age at natural menopause and risk of ischemic stroke: the Framingham heart study. Stroke 40: 1044-1049, 2009.

LIU Y, MATTSSON L, WIKLUND D: Macrophages isolated from human atherosclerotic plaques produce IL-8, and oxysterol may have a regulatory function for IL-8 production. Arterioscler Thromb Vasc Biol 17: 317-323, 1997.

MALLAT Z, TALEB S, AIT-OUFELLA H, TEDGUI A: The role of adaptive T cell immunity in atherosclerosis. J Lipid Res 50 (Suppl): S364-S369, 2009.

MATTHEWS AJ, VERCELLOTTI GM, MENCHACA HJ, BLOCH PH, MICHALEK VN, MARKER PH, MURAR J, BUCHWALD H: Iron and atherosclerosis: inhibition by the iron chelator deferiprone (L1). J Surg Res 73: 35-40, 1997.

MEDBURY HJ, JAMES V, NGO J, HITOS K, WANG Y, HARRIS DC, FLETCHER JP: Differing association of macrophage subsets with atherosclerotic plaque stability. Int Angiol 32: 74-84, 2013.

MEYERS DG, JENSEN KC, MENITOVE JE: A historical cohort study of the effect of lowering body iron through blood donation on incident cardiac events. Transfusion 42: 1135-1139, 2002.

MICHA R, MICHAS G, MOZAFFARIAN D: Unprocessed red and processed meats and risk of coronary artery disease and type 2 diabetes - an updated review of the evidence. Curr Atheroscler Rep 14: 515-524, 2012.

MILLER M, HUTCHINS GM: Hemochromatosis, multiorgan hemosiderosis and coronary artery disease. JAMA 272: 231-233, 1994.

MORISAKI N, KOYAMA N, KAWANO M, MORI S, UMEMIYA K, KOSHIKAWA T, SAITO Y, YOSHIDA S: Human macrophages modulate the phenotype of cultured rabbit aortic smooth muscle cells through secretion of platelet-derived growth factor. Eur J Clin Invest 22: 461-468, 1992.

NAITO Y, TAKAGI T, HIGASHIMURA Y: Heme oxygenase-1 and anti-inflammatory M2 macrophages. Arch Biochem Biophys 564: 83-88, 2014.

NJAJOU OT, HOLLANDER M, KOUDSTAAL PJ, HOFMAN A, WITTEMAN JC, BRETELER MM, VAN DUIJN CM: Mutations in the hemochromatosis gene (HFE) and stroke. Stroke 23: 2363-2366, 2002.

NJAJOU OT, KANAYA AM, HOLOVET P, CONELLY S, STROTMEYER ES, HARRIS TB, CUMMINGS SR, HSUEH WC: Association between oxidized LDL, obesity and type 2 diabetes in population-based cohort, the Health, Aging and Body Composition Study. Diabetes Metab Res Rev 25: 733-739, 2009.

OUYANG P, VAIDYA, D, DOBS A, GOLDEN SH, SZKLO M, HECKBERT SR, KOPP P, GAPSTUR SM: Sex hormone levels and subclinical atherosclerosis in postmenopausal women: the multi-ethnic study of atherosclerosis. Atherosclerosis 204: 255-261, 2009. 
PAINE A, EIZ-VESPER B, BLASCZYK R, IMMENSCHUH S: Signaling to heme-oxygenase-1 and its anti-inflammatory therapeutical potential. Biochem Pharmacol 80: 1895-1903, 2010.

PARTHASARATHY S, RAGHAVAMENON A, GARELNABI MO, SANTANAM N: Oxidized low-density lipoprotein. Methods Mol Biol 610: 403-417, 2010.

PASTERKAMP G, VAN KEULEN JK, DE KLEIJN DP: Role of Toll-like receptor 4 in the initiation and progression of atherosclerotic disease. Eur J Clin Invest 34: 328-334, 2004.

PRATICÓ D, PASIN M, BARRY OP, GHISELLI A, SABATINO G, IULIANO L, FITZGERALD GA, VIOLI F: Iron-dependent human platelet activation and hydroxyl radical formation: involvement of protein kinase $\mathrm{C}$. Circulation 99: 3118-3122, 1999.

RASMUSSEN ML, FOLSOM AR, CATELLIER DF, TSAI MY, GARG U, ECKFELDT JH: A prospective study of coronary heart disease and the hemochromatosis gene (HFE) C282Y mutation: the Atherosclerosis Risk in Communities (ARIC) study. Atherosclerosis 154: 739-746, 2001.

RECALCATI S, INVERNIZZI P, AROSIO P, CAIRO G: New functions for an iron storage protein: the role of ferritin in immunity and autoimmunity. J Autoimmun 30: 84-89, 2008.

RECALCATI S, LOCATI M, MARINI A, SANTAMBROGIO P, ZANINOTTO F, DE PIZZOL M, ZAMMATARO L, GIRELLI D, CAIRO G: Differential regulation of iron homeostasis during human macrophage polarized activation. Eur J Immunol 40: 824-835, 2010.

REN S, SHATADAL S, SHEN GX: Protein kinase C-beta mediates lipoprotein-induced generation of PAI-1from vascular endothelial cells. Am J Physiol 278: E656-E662, 2000.

RIŠKO P, PLÁTENÍK J, BUCHAL R, POTOČKOVÁ J, KRAML PJ: The labile iron pool in monocytes reflects the activity of the atherosclerotic process in men with chronic cardiovascular disease. Physiol Res 66: 49-61, 2017.

ROEST M, VAN DER SCHOUW YT, DE VALK B, MARX JJ, TEMPELMAN MJ, DE DROOT PG, SIXMA JJ, BANGA JD: Heterozygosity for hereditary hemochromatosis gene is associated with cardiovascular death in women. Circulation 100: 1268-1273, 1999.

SACKETT K, CUNDERLIK M, SAHNI N, KILLEEN AA, OLSON AP: Extreme hyperferritinemia: causes and impact on diagnostic reasoning. Am J Clin Pathol 145: 646-650, 2016.

SALONEN JT, NYYSSÖNEN K, KORPELA H, TUOMILEHTO J, SEPPÄNEN R, SALONEN R: High store iron levels are associated with excess risk of myocardial infarction in eastern Finnish men. Circulation 86: 803-811, 1992.

SALONEN JT, TUOMAINEN TP, SALONEN R, LAKKA TA, NYYSSÖNEN K: Donation of blood is associated with reduced risk of myocardial infarction. The Kuopio Ischaemic Heart Disease Risk Factor Study. Am $J$ Epidemiol 148: 445-451, 1998.

SARNAK MJ, TIQHIOUART H, MANJUNATH G, MACLEOD B, GRIFFITH J, SALEM D, LEVEY S: Anemia as a risk factor for cardiovascular disease in the Atherosclerosis Risk in Communities (ARIC) Study. $J$ Am Coll Cardiol 40: 27-33, 2002.

SATCHELL L, LEAKE DS: Oxidation of low-density lipoprotein by iron at lysosomal pH: implications for atherosclerosis. Biochemistry 51: 3767-3775, 2012.

SHOJI T, NIHATA K, FUKUMA S, FUKUHARA S, AKIZAWA T, INABA M: Both low and high serum ferritin levels predict mortality risk in hemodialysis patients without inflammation. Clin Exp Nephrol 2016. doi: 10.1007/s10157-016-1317-1

SNOWDON DA, PHILLIPS RL, FRASER GA: Meat consumption and fatal ischemic heart disease. Prev Med 13: 490-500, 1984.

STEINBERG D, PARTHASARATHY S, CAREW TE, KHOO JC, WITZTUM J: Beyond cholesterol: modifications of low-density lipoprotein that increase its atherogenicity. $N$ Eng J Med 320: 915-924, 1989.

STOCKER R, YAMAMOTO Y, MCDONAGH AF, GLAZER AN, AMES BN: Bilirubin is an antioxidant of possible physiological importance. Science 235: 1043-1046, 1987.

SULLIVAN JL: Iron and sex difference in heart disease risk. Lancet 1: 1293-1294, 1981.

SYROVÁTKA P, KRAML P, HULÍKOVÁ K, FIALOVÁ L, VEJRAŽKA M, CRKOVSKÁ J, POTOČKOVÁ J, ANDĚL M: Iron stores are associated with asymptomatic atherosclerosis in healthy men of primary prevention. Eur J Clin Invest 41: 846-853, 2011. 
TROESCH B, EGLI I, ZEDER C, HURRELL RF, DE PEE S, ZIMMERMANN MB: Optimization of a phytasecontaining micronutrient powder with low amounts of highly bioavailable iron for in-home fortification of complementary foods. Am J Clin Nutr 89: 539-544, 2009.

TUOMAINEN TP, PUNNONEN K, NYYSSÖNEN K, SALONEN JT: Association between body iron stores and risk of acute myocardial infarction in men. Circulation 97: 1461-1466, 1998.

TUOMAINEN TP, KONTULA K, NYYSSONEN K, LAKKA TA, HELIÖ T, SALONEN JT: Increased risk of acute myocardial infarction in carriers of the hemochromatosis gene Cys282Tyr mutation: a prospective cohort study in men in eastern Finland. Circulation 100: 1274-1279, 1999.

VALENTI L, DONGIOVANNI P, MOTTA BM, SWINKELS DW, BONARA P, RAMETTA R, BURDICK L, FRUGONI C, FRANCANZANI AL, FARGION S: Serum hepcidin and macrophage iron correlate with MCP-1 release and vascular damage in patients with metabolic syndrome alterations. Arterioscler Thromb Vasc Biol 31: 683-690, 2011.

VAN DER A DL, ROVERS MM, GROBBEE DE, MARX JJ, WAALEN J, ELLERVIK C, NORDESTGAARD BG, OLYNYK JK, MILLS PR, SHEPHERD J, GRANDCHAMP B, BOER JM, CARUSO C, ARCA M, MEYER BJ, VAN DEN SCHOUW YT: Mutations of the HFE gene and cardiovascular disease risk: an individual patient data meta-analysis of 53880 subjects. Circ Cardiovasc Genet 1: 43-50, 2008.

WAALEN J, FELITTI V, GELBART T, HO NJ, BEUTLER E: Prevalence of coronary heart disease associated with HFE mutation in adults attending a health appraisal center. Am J Med 113: 472-479, 2002.

WELLONS M, OUYANG PM, SCHREINER PJ, HERRINGTON DM, VAIDYA D: Early menopause predicts future coronary heart disease and stroke: the multi-ethnic study of atherosclerosis. Menopause 19: 1081-1087, 2012.

WESSELIUS LJ, NELSON ME, SKIKNE BS: Increased release of ferritin and iron by iron-loaded alveolar macrophages in cigarette smokers. Am J Respir Crit Care Med 150: 690-695, 1994.

WHITTINGTON C: Genetics of hereditary hemochromatosis. BCMJ 44: 544-546, 2002.

WOLK A: Potential health hazards of eating red meat. J Intern Med 281: 106-122, 2017.

WONG CM, PRESTON IR, HILL NS, SUZUKI YJ: Iron chelation inhibits the development of pulmonary vascular remodeling. Free Radic Biol Med 53: 1738-1747, 2012.

XIONG S, SHE H, TAKEUCHI H, HAN B, ENGELHARDT JF, BARTON CH, ZANDI E, GIULIVI C,

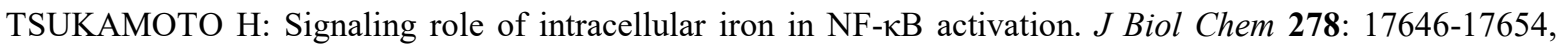
2003.

YUAN X, CONG Y, HAO J, SHAN Y, WANG S, CHEN J: Regulation of LIP level and ROS formation through interaction of H-ferritin with G-CSF receptor. J Mol Biol 339: 131-144, 2004.

YUAN XM, ANDERS WL, OLSSON AG, BRUNK UT: Iron in human atheroma and LDL oxidation by macrophages following erythrophagocytosis. Atherosclerosis 124: 61-73, 1996.

ZACHARSKI LR, CHOW BK, HOWES PS, SHAMAYEVA G, BARON JA, DALMAN RL, MALENKA DJ, OZAKI CK, LAVORI PW: Reduction of iron stores and cardiovascular outcomes in patients with peripheral arterial disease: a randomized control trial. JAMA 297: 603-610, 2007.

ZHU Y, HOJO Y, IKEDA U, TAKAHASHI M, SHIMADA K: Interaction between monocytes and vascular smooth muscle cells enhances matrix metalloproteinase-1 production. J Cardiovasc Pharmacol 36: 152-161, 2000. 